\title{
Comparison of embodied energies of Ordinary Portland Cement with Bayer-derived geopolymer products
}

\section{$\operatorname{AUTHOR}(\mathrm{S}):$}

Jamieson, Evan; McLellan, Benjamin; Van Riessen, Arie; Nikraz, Hamid

\section{CITATION:}

Jamieson, Evan ...[et al]. Comparison of embodied energies of Ordinary Portland Cement with Bayer-derived geopolymer products. Journal of Cleaner Production 2015, 99: 112-

\section{ISSUE DATE:}

2015-07-15

URL:

http://hdl.handle.net/2433/236031

\section{RIGHT:}

(c) 2015. This manuscript version is made available under the CC-BY-NC-ND 4.0 license

http://creativecommons.org/licenses/by-nc-nd/4.0/; The full-text file will be made open to the public on 15 July 2017 in accordance with publisher's 'Terms and Conditions for Self-Archiving';: この論文は出版社版でありません。引用の際に は出版社版をご確認ご利用ください。; This is not the published version. Please cite only the published version. 


\title{
Comparison of embodied energies of Ordinary Portland Cement with Bayer-derived Geopolymer products
}

\author{
Evan Jamieson *1\&4, Benjamin McLellan², Arie van Riessen ${ }^{3}$, Hamid Nikraz . \\ 1,Technology Delivery Group, Alcoa of Australia, PO Box 161, Kwinana, WA, 6966, AUSTRALIA. \\ 2, Graduate School of Energy Science, Kyoto University, Yoshida-honmachi, Sakyo-ku, Kyoto 606-8501, Japan. \\ 3,Geopolymer Group, Curtin University, GPO Box U1987, Perth, WA, 6845, AUSTRALIA. \\ 4, Department of Civil Engineering, Curtin University, GPO Box U1987, Perth, WA, 6845, AUSTRALIA.
}

\begin{abstract}
It has been shown that silicate-derived geopolymers can be manufactured with lower greenhouse gas emissions than can Ordinary Portland Cement (OPC). This is assuming that transport methods and distances are equal. In this paper, we have used published and newly-determined data, following closely with accepted life cycle assessment procedures, to evaluate the embodied energy of a new class of geopolymers, namely Bayer-derived geopolymers. These geopolymers utilise concentrated sodium aluminate solutions (Bayer liquor) with fly ash and other aluminosilicates to form geopolymers. Significantly, utilising this combination of industrial byproducts can dramatically lower the embodied energy of Bayer-derived geopolymer. Under current industrial operations, Bayer liquor is recycled into the process after intensive treatment, in order to retain alumina and caustic soda however, under alternative configurations this impurity-laden stream could be removed, potentially enhancing environmental performance of both geopolymer and alumina production. In a reconfigured-system, with no allocation of embodied energy to the Bayer waste stream, this could reduce the embodied energy of the derived geopolymer concrete to as little as $0.27 \mathrm{GJ} / \mathrm{t}$. Embodied energies of between 6 and 30\% of those associated with OPC have been achieved depending on the process configuration and allocation assumptions used. Most importantly, such assessment indicates that for the first time, Bayer-derived geopolymer binders could be produced with embodied energy intensity at levels comparable to manufactured or recycled sand, gravel and stone.
\end{abstract}

Keywords: geopolymer, Bayer liquor, cement, bauxite residue, alumina, embodied energy

\section{Introduction}

Geopolymers are claimed to have a much smaller environmental footprint than Ordinary Portland Cement (OPC) based largely on the ability to reduce the carbon footprint through lower embodied energy and elimination of $\mathrm{CO}_{2}$ emissions from clinker calcination. In this paper we will use embodied energy as the 
measure for comparison of the environmental impact, in order to compare OPC with a new material derived from Bayer-liquor, a waste stream from the processing of bauxite to alumina.

There are many different ways to calculate this embodied energy and each method is reliant on assumptions, circumstances and inclusion of processing stages (Dixit et al., 2010). For example, it can be claimed that the embodied energy of concrete is quite low as it only contains around 15\% OPC (dry weight) and most of the remainder is low energy aggregate (Prusinski et al., 2006). While this is true, the fact remains that carbon dioxide $\left(\mathrm{CO}_{2}\right)$ release from cement production is a significant proportion of that derived from human activity globally (Nature Materials, 2007; Allwood et al., 2010).There are also claims that OPC concretes have become less energy intensive, by utilising higher levels of pozzolanic materials such as fly ash (O’Brien et al., 2009; Huntzinger \& Eatmon, 2009 ), higher efficiency kilns (van den Heede \& de Belie, 2012) and by wider use of renewable energy sources (CCAA, 2010). However, it is rare to capture the full energy cost of OPC.

Some assessments of geopolymers have been particularly favourable. For instance, Davidovits (1994) claims that geopolymers have between 10 and 20\% of the carbon footprint of OPC, while Wimpenny (2009) reported that geopolymers have only about 30\% of the carbon footprint of OPC, a figure in line with that quoted by Weil et al. (2009). From the industrial perspective, the geopolymer concrete manufacturer of E-Crete ${ }^{\mathrm{TM}}$ made a life cycle assessment of their product and concluded that it "reduces the $\mathrm{CO}_{2}$ footprint of cement by $80 \%$ " (Zeobond, 2012). Van Deventer et al. (2012) notes that this value is a "binder to binder" comparison whereas a "concrete to concrete" comparison results in a $60 \% \mathrm{CO}_{2}$ reduction. Wagners Concrete Pty Ltd (2012) state their Earth Friendly Concrete binder reduces the carbon emissions by 80-90\% compared to those of OPC. Yang et al. (2013) compared normal OPC, OPC with supplementary cementitious materials (OPC+SCM) and a variety of alkali activated concretes (geopolymer binders) of similar compressive strength. With the OPC mixture being $100 \%$ of carbon emissions, OPC+SCM resulted in a 20\% reduction while geopolymer concretes gave between a $55 \%$ and $75 \%$ reduction.

Not all assessments have shown as great an improvement, however, with much of the difference occurring due to the system boundaries, geographical limitations, specific mix ratios and the functional unit of comparison (e.g. $\mathrm{kg}$ of binder, $\mathrm{m}^{3}$ of concrete, etc.). Some of the key drivers of impact in the embodied energy and emissions from the production of geopolymers are the impacts associated with the production of feed-stocks - particularly activating compounds (e.g. $\mathrm{NaOH}$ and sodium silicate). A detailed life-cycle impact assessment for standard geopolymer production demonstrated that the use of sodium silicate as an alkali activator has a large environmental impact (Habert et al., 2010). Furthermore, fly ash and blast furnace slag based geopolymers have lower environmental impacts than metakaolin based geopolymer, as both are considered to be waste materials and thus assigned very low embodied energies. Habert et al. (2010) demonstrated that their geopolymer formulations achieved a $60 \%$ reduction in $\mathrm{CO}_{2}$ emissions compared with those of OPC.

McLellan et al. (2011) compared the carbon impacts from OPC concrete and geopolymer concrete in an Australian context, with particular focus on the transportation and grid emissions that can exacerbate or alleviate the energy-related impacts of geopolymer feed-stocks. This placed a heavy emphasis upon transport as a contributor to the life cycle analysis. They reported a wide range of environmental costs and benefits based upon the source material and mode of transport. Following a series of case studies they were able to demonstrate that 
using typical Australian feed-stocks there was a potential $40 \%$ to $60 \%$ reduction in greenhouse gas emissions compared to OPC. It was noted that the production of sodium hydroxide and sodium silicate was a major contributing factor to the carbon footprint as well as to cost. Because of the inherent variability in reported comparisons with OPC carbon footprint, it is important to quote the actual embodied energy of the products being compared.

The general conclusion of most recent studies on geopolymers and other cement alternatives has been that the inclusion of materials from waste streams (such as fly ash or slag) tends to provide multiple benefits to the overall systemic environmental impacts as well as to the cost. The minerals industry offers a number of such waste streams that may contribute as activating components or as aggregate in geopolymers. For instance, based on global minerals production figures (USGS, 2011; IEA, 2010):

- at an estimated rate of $0.3 \mathrm{t}$ slag /t steel, the global steel industry (1420 Mtpa raw steel (USGS, 2011)) could contribute approximately 420 Mtpa of slag;

- with an ash content of 15\%, the global coal industry (7273.3 Mtpa of coal (BP, 2011)) could contribute approximately 1090 Mtpa of ash.

If these were considered to be entirely economically and technically viable sources of supplementary cementitious material, the combined waste materials from these two industries alone would account for approximately 45\% of global cement production (3310 Mtpa in 2010) (USGS, 2011). Thus, there is currently an ample supply of useful material being largely wasted, which could be transformed into geopolymer or used to supplement cement clinker.

The importance of mineral waste streams is further shown by the fact that, at a rate of 2-3 tonnes per tonne of product, the global aluminium industry produces approximately 160 Mtpa of bauxite residue (IAI, 2007). The coarse fraction of this residue, Red Sand ${ }^{\mathrm{TM}}$, can be used as a substitute for fine aggregate in concrete (Wahyuni et al. 2006). Perhaps more importantly, the alumina production process (Bayer process) involves the utilisation of a concentrated solution of alumina and sodium hydroxide, which under certain circumstances could be utilised as an aluminate activator for geopolymer production (Jamieson, 2008). Utilisation of industrially produced Bayer liquor for the activation of geopolymers could radically reduce the embodied energy of the final product, as well as significantly reduce cost structures.

Experimentally, geopolymers have been produced with alternative reagents such as sodium aluminate solution (Jamieson, 2008; Phair \& van Deventer, 2002). Moreover, the production of Bayer-derived geopolymers has recently met potential application milestones (Jamieson et al., 2012; van Riessen et al., 2013). As the potential for product commercialisation appears to grow closer, an investigation into the embodied energy of this class of product is timely, and is novel in that this assessment has yet to be undertaken anywhere (to the best of the authors`knowledge).

This background review of the literature reveals three important issues that indicate the importance of the current study. Firstly, there is wide variation in the calculated benefits of geopolymers - and it is important to undertake embodied energy and carbon footprint studies for specific new products with care as to the assumptions, functional unit and boundaries. Secondly, waste streams are potentially important contributors to 
reducing the global impact of cement - and one such stream that is currently not widely utilised is bauxite residue from the aluminium industry. Thirdly, that alumino-silicate activation of geopolymers using additional aluminium industry process streams such as Bayer liquor are technically feasible and require assessment. Therefore, in this paper, the embodied energy for this new class of geopolymer is calculated and the results are compared with that of OPC.

\section{Materials and Methods}

This study combines experimental research results with process engineering and theoretical calculations of the embodied energy. Fundamental to the results is the experimental component, which has actually demonstrated the development of BDG`s in the laboratory. To compare the embodied energy of a BDG with that of published silicate-derived geopolymers and OPC, the groundwork for that comparison needs to be documented. As this is a new material, this section describes the material characteristics and process of production for clarity.

Bayer liquor (known in the industry as "spent") was processed to achieve a concentration of $230 \mathrm{~g} / \mathrm{L}$ alumina (as $\mathrm{Al}_{2} \mathrm{O}_{3}$, but in the form of $\mathrm{Al}(\mathrm{OH})_{4}^{-}$) and $400 \mathrm{~g} / \mathrm{L}$ caustic (as $\mathrm{NaOH}$ ). This liquor was used as an alternative low embodied energy activator in the development of a geopolymer concrete. The Bayer-derived geopolymer concrete formulation utilised here and targeted to have a compressive strength of $25 \mathrm{MPa}$, is shown in Table 1 alongside the compared OPC concrete formulation.

The approach outlined below is based on an "ex-gate" process. That is, the reagents for both geopolymer and OPC concretes will be assumed to be on location - or in other words, the assumed distance of transport for each of the feed stocks is zero kilometres. This is not true in practice, but both concrete manufacturing processes will require delivery of sand, aggregate, etc., from various locations. Without a specific representative case study, the preferable method is to assume that the distances will be similar for both processes and assign them to zero. For this investigation we have started with the assumption that the binder for both forms of concrete is approximately 17\% w/w but acknowledge specific cases will be different (McLellan et al., 2011). Both concrete formulations will usually include admixtures (additives designed to enhance performance), but van den Heede and De Belie (2012) note that the $\mathrm{CO}_{2}$ foot print of admixtures is slightly lower than OPC and the actual amount of super-plasticiser use is almost negligible. In fact a literature review showed that the environmental impact of admixtures was negligible (Habert et al., 2010) hence the impact of admixtures is ignored for these calculations. What is remarkable for the Bayer-derived geopolymer formulation is that Bayer liquor, fly ash, silica fume and possibly the sand, are all industrial by-products. Such waste products provide a triple benefit when used in geopolymers, in that they reduce the requirement for both waste storage and extraction of raw materials, to produce cement while concurrently providing potential reductions in greenhouse gas emissions.

\section{Theory/calculation}

\subsection{Embodied energy calculation}


The embodied energies of the OPC and BDG were calculated using data gathered primarily from the academic literature supplemented by industrial sources or estimations where necessary. There is a wide range of alternative embodied energy figures for many of the feedstocks - with a factor of two being a typical difference between the lower and upper estimates. The assumed values used here were those which were judged to be most reasonable and reliable for the case study at hand. Table 2 presents the selected values, as well as the range of values reported for comparison. The following paragraphs offer a brief description of the processes which contribute to the embodied energy of the feedstocks.

OPC production mainly involves the combination of clay and limestone, which are ground then blended, then calcined (clinker) before being milled. Finally gypsum is added to form the cement product. This cement is then often blended with supplementary cementitious materials (SCM) such as fly ash to give a final product. For the purpose of this study, we consider the mining of clay and limestone and the clinker calcining and milling, and have ignored the intermediate transport of feedstocks. The overall embodied energy of OPC is therefore the sum of the embodied energy for the production of clay and limestone and the processing of this feedstock into OPC. Similarly, for lime, the embodied energy consists of the mining of limestone feedstock and the calcining and milling of the lime. For the current study, global average mining energy usage of around $0.1 \mathrm{GJ} / \mathrm{t}$ is assumed for both limestone and clay (McLellan et al., 2012). The embodied energy for production of OPC depends significantly on the technology associated with the kiln operation. The weighted average energy intensity from the International Energy Agency`s global examination of energy efficiency in the industry (IEA, 2007) is utilised here due to the wide coverage of the study and the global weighting. It is likely that this will give a conservative (lower embodied energy) than most other figures, making the comparison with BDG likewise a conservative estimate.

The embodied energy of the aggregate material varies significantly depending on the source and type of aggregate. A range of values have been reported from 0.02 to $0.5 \mathrm{GJ} / \mathrm{t}$ for aggregate (Langer, 2009). If minimal processing is assumed, this figure is likely to be towards the lower end of the scale, whilst greater crushing, separation or shape adjustment, and the extraction of aggregate from deeper, less pure or more complex deposits will increase energy requirements. In the current study we have utilised $0.1 \mathrm{GJ} / \mathrm{t}$ as representative, however the importance of aggregate is to the total embodied energy rather than to the comparison, as the amount of aggregate will be equal in both OPC and BDG products.

Low grade silica fume and fly ash are both waste products which require particularly low amounts of energy for capture - and in fact may arguably be given a zero energy allocation if we consider their capture as a waste treatment process. However, if it is required to reclaim these mineral wastes from storage dams, or if particularly high levels of separation are required to ensure feedstock properties, a higher level of energy is required (estimated at $0.1 \mathrm{GJ} / \mathrm{t}$ for re-mining) (McLellan et al., 2011, 2012). We have taken the middle ground for the purpose of this study $(0.05 \mathrm{GJ} / \mathrm{t})$, as the process would be to utilise newly produced material rather than mine the stockpile. 
The difficulty with calculating the embodied energy of Bayer-derived geopolymer is the determination of the embodied energy of the Bayer liquor. This has been attempted by several methods to determine the validity of the numbers used, as described in the following section. The fundamental methodology uses a life cycle assessment (LCA) process to allocate impacts to the liquor, using mass-based and value-based allocation methods.

Beside the embodied energy of the feedstock the energy required for mixing, pumping and laying concrete (of either variety) is estimated to be $0.1 \mathrm{GJ} / \mathrm{t}$. Using this data, we can then calculate the embodied energy of the alternative concrete mixes.

\subsection{Determining the embodied energy of Bayer liquor feedstock}

Production of Bayer-flyash geopolymers requires the utilisation of a processed Bayer liquor. Calculating the embodied energy of the Bayer liquor and subsequent processing is a non-trivial task. The entire Bayer process is about recirculating the caustic aluminate stream while managing temperature and solubility of gibbsite (hydrate $\mathrm{Al}_{2} \mathrm{O}_{3} \cdot 3 \mathrm{H}_{2} \mathrm{O}$ ). Bayer geopolymer feedstock itself must be extracted from spent Bayer liquor before it is suitable for geopolymer activation as shown in Figure 1.

The starting point in the calculation is to identify the active components within the Bayer liquor feedstock. Terminology within the Bayer industry has a meaning of its own, so we will use scientific definitions where possible. The Bayer feedstock active ingredients consist of alumina and sodium hydroxide. The hydroxide can be separated into freely dissociated and bound with aluminate The components are separated and listed as follows.

- $230 \mathrm{~g} / \mathrm{L}$ alumina (as $\mathrm{Al}_{2} \mathrm{O}_{3}$ ) in the form of $\mathrm{Al}(\mathrm{OH})^{4-}$

- $220 \mathrm{~g} / \mathrm{L}$ caustic soda $(\mathrm{NaOH})$ in the form of $\mathrm{Na}^{+} \mathrm{OH}^{-}$.

- $180 \mathrm{~g} / \mathrm{L}$ caustic soda (as $\mathrm{NaOH})$ in the form of $\mathrm{Al}(\mathrm{OH})_{4}^{-}$.

Preparation of Bayer feedstock from Bayer liquor has a significant energy requirement that must also be accounted for.

The determination of the caustic embodied energy is as follows. Bayer liquor is made utilising a 50\% solution of sodium hydroxide derived from the Chlor-alkali process (European Commission, 2001). For this study we have utilised a value of $5.7 \mathrm{GJ} / \mathrm{t}$ for the embodied energy of $\mathrm{NaOH}$ solution. Hence, the contribution of sodium hydroxide to the embodied energy of the Bayer liquor feedstock is $2.3 \mathrm{GJ} / \mathrm{m}^{3}$. As the density of the feedstock is $1.6 \mathrm{t} / \mathrm{m}^{3}$, the embodied energy of Bayer feedstock from sodium hydroxide is $1.4 \mathrm{GJ} / \mathrm{t}$.

Calculating the embodied energy of dissolved alumina from the Bayer process is more problematic; some estimates are given below.

1) In a Commonwealth Government of Australia (2000) report on the energy efficiency of the alumina industry, it is claimed that alumina has an embodied energy of $11 \mathrm{GJ} / \mathrm{t}$. However, alumina is a precipitated, filtered, washed, dried and calcined version of the alumina in Bayer liquor. Using an 
energy figure for calcination of $3.9 \mathrm{GJ} / \mathrm{t}$ (Smith et al., 2007), then the embodied energy for alumina in Bayer liquor can be estimated to be $7.1 \mathrm{GJ} / \mathrm{t}$.

2) Smith et al. (2007) reported an alternative embodied energy for calcined alumina as $12.3 \mathrm{GJ} / \mathrm{t}$. Subtracting the energy for calcination (3.9 GJ/t) the embodied energy for alumina in Bayer liquor would be $8.4 \mathrm{GJ} / \mathrm{t}$.

3) The International Aluminium Institute (IAI, 2012) has collected the embodied energy for the production of "hydrate" (the product before calcination) over recent years; this is published here for the first time as being $8.9 \mathrm{GJ} / \mathrm{t}$. This figure is a maximum as the embodied energy of solution hydrate does not include the steps of precipitation, filtration, washing and drying.

Given that the IAI figure is based on data from $57 \%$ of world production, this would be considered to be the most reliable. The figure does not include a mining component which has been reported by (Smith et al., 2007) to be $0.04 \mathrm{GJ} / \mathrm{t}$ bauxite. It takes 2-3 tonnes of bauxite to produce a tonne of alumina, so a figure of $0.1 \mathrm{GJ} / \mathrm{t}$ will be added to the IAI number. Hence we will use $9.0 \mathrm{GJ} / \mathrm{t}$ as a maximum conservative estimate of the embodied energy for dissolved alumina in Bayer liquor.

We are now able to calculate the contribution of dissolved alumina to the Bayer liquor feedstock. This equates to $2.1 \mathrm{GJ} / \mathrm{m}^{3}$ of feedstock, or $1.3 \mathrm{GJ} / \mathrm{t}$ (feedstock density $1.6 \mathrm{t} / \mathrm{m}^{3}$ ). The active components of Bayer liquor feedstock combine to $2.7 \mathrm{GJ} / \mathrm{t}$ of indirect embodied energy. Furthermore, the Bayer liquor feedstock has been processed from Bayer spent liquor and this processing has a direct energy cost of $0.8 \mathrm{GJ} / \mathrm{t}$.

Thus the final embodied energy for Bayer liquor feedstock is found to be $3.5 \mathrm{GJ} / \mathrm{t}$. 


\section{Results and discussion}

A comparison of the embodied energy of OPC concrete and Bayer geopolymer concrete is dependent upon the assumptions used and the actual products compared. Here we quantify comparisons based upon different assumptions and upon different products. There is also a brief evaluation of the potential implications should Bayer-flyash geopolymer be significantly utilised.

\subsection{Embodied energy of concrete formulations.}

The embodied energy figures for the feedstock materials are now applied to specific concrete formulations. Some specialised OPC concretes will utilise fly ash or lime, however for this comparison, a standard concrete dry mix ratio as shown in Table 3 is utilised.

This analysis shows that the Bayer derived geopolymer concrete is only 33\% of the embodied energy of OPC concrete. The geopolymer is a stiff mixture but still flows well with applied vibration. Care is needed for comparison with other published data, because they often only quote carbon dioxide equivalents and not the embodied energy.

It is very easy to change the comparison by changing the starting assumptions for concrete formulations. For example if we add a significant transport cost to the sand and aggregate components, the comparative advantage is reduced (McLellan et al., 2011).

\subsection{Embodied energy of binding agent}

A simplified method of comparison is to look at embodied energy of the binder alone. By using such an approach, the potential user can readily calculate the relative change in embodied energy based on alternative binder ratios.

Using the same formulation for Bayer-derived geopolymer binder, we have a binder agent embodied energy of $0.9 \mathrm{GJ} / \mathrm{t}$ compared to OPC binder with an embodied energy of $4.9 \mathrm{GJ} / \mathrm{t}$. In this comparison, the embodied energy of Bayer derived geopolymer is only $18 \%$ of that of OPC.

\subsection{Bayer liquor as a waste product}

In the previous two sections it was demonstrated that Bayer-derived geopolymer would have a significant embodied energy advantage over OPC. Here, a further argument can be made to enhance this advantage.

Bayer liquor is a sodium hydroxide solution that is mixed with crushed bauxite and heated with pressure to extract alumina from the ore. The un-reacted solids are removed and the liquor is cooled in the presence of alumina seed crystals to encourage precipitation. Once the precipitated alumina is removed, the liquor is recycled (Figure 1). During the process, many types of organic and inorganic impurities build up within the recirculating caustic liquor. A large portion of the Bayer process is designed to prevent loss of the liquor and also to maintain a manageable level of impurities. 
As shown by Jamieson (2008), the removal of Bayer liquor from the Bayer process circuit and its replacement with fresh caustic is, effectively, an impurity removal process. The question is, "What to do with this heavily impurity laden sodium aluminate solution?” In some cases, the liquor is burnt to remove the organic species with the remaining solids going back to process. However, inorganic impurities must be dealt with by other processes. It is thus argued that Bayer liquor should be treated as a waste material and the energy utilised for its manufacture be attributed to the Bayer process production of alumina (following standard LCA protocols. In this case, the embodied energy of the Bayer liquor bleed stream could reasonably be attributed a value of $0 \mathrm{GJ} / \mathrm{t}$, leaving just the direct energy required to process the liquor to make it a suitable geopolymer feedstock. This would give an overall embodied energy of Bayer liquor feedstock of $0.78 \mathrm{GJ} / \mathrm{t}$.

(Note that the use of Bayer liquor bleed stream for geopolymer production may result in a lowering of the recirculation Bayer liquor impurity load. This could lead to closure of other more energy intensive impurity removal processes resulting in the overall lowering of the embodied energy of the produced alumina. This has not been accounted for here).

With the same approach as above for the binding agent alone, the calculated embodied energy of Bayer-derived geopolymer binder is $0.27 \mathrm{G} / \mathrm{t}$, where the Bayer liquor is assigned as waste and given a zero embodied energy allocation.

By assuming that Bayer liquor feedstock is a process waste, the embodied energy of one tonne of Bayer derived geopolymer paste is $0.27 \mathrm{GJ} / \mathrm{t}$ and represents only $6 \%$ of the embodied energy of OPC. This implies that, for the first time, we can discuss binding agents within the same embodied energy range as manufactured sand (Langer, 2009), gravel (Hammond \& Jones, 2008a) and recycled stone (Hammond \& Jones, 2011).

\subsection{Global potential}

Evaluation of the global impact is contingent upon a series of variables. These include the rate of uptake within global plants, their impurity load, the geographical location to markets, the cost of caustic and value of alumina. Making a series of conservative estimates results in an average available Bayer liquor feedstock volume of $0.012 \mathrm{~kL} / \mathrm{t}$, or $0.02 \mathrm{t} / \mathrm{t}$ alumina produced. The estimated alumina production in 2011 was 92 million tonnes; hence the mass of Bayer geopolymer feedstock liquor is 1.8 million tonnes. Given that Bayer feedstock equates to about $25 \%$ of binder paste, there is the potential to make 7.3 million tonnes of Bayer derived geopolymer binder.

Given that cement production in 2010 was 3310 million tonnes, uptake of Bayer derived geopolymer would equate to less than $1 \%$ of the global market. This may seem small, but is an appropriate entry level into the market. With market forces and a carbon rated economy, this value could be significantly higher, especially as other by-product sources of caustic could come to market.

\section{Conclusions}


The determination of the embodied energy of a product depends on many assumptions. Reporting these assumptions and how they are derived is essential.

In this case, two methods of calculating the embodied energy of "hydrate" in Bayer liquor were used. They compared favourably with industry collected data which was reported for the first time from the International Aluminium Institute. Once the energy of mining is included, that figure is put at a value of $<9.0 \mathrm{GJ} / \mathrm{t}$ of $\mathrm{Al}(\mathrm{OH})_{3}$.

The embodied energy to produce hydrate, caustic and the energy used to process Bayer liquor into a geopolymer feedstock are combined to provide an embodied energy for Bayer liquor feedstock of 3.5GJ/t.

A new class of construction material, "Bayer derived geopolymer”, was then assessed and the embodied energy calculated for binder paste was $0.9 \mathrm{GJ} / \mathrm{t}$, while the embodied energy for a subsequent concrete product was 0.34 $\mathrm{GJ} / \mathrm{t}$.

It is further argued that the Bayer liquor feedstock can be considered as an impurity removal waste product and should be assigned an embodied energy of zero at the point of it leaving the alumina production process, as is fly ash and other waste streams. In this case, the embodied energy of geopolymer paste made utilising Bayer liquor feedstock would be $0.27 \mathrm{GJ} / \mathrm{t}$.

Under these assumptions, this Bayer derived geopolymer represents as little as 6\% of the embodied energy of Ordinary Portland Cement on a weight for weight basis.

These conclusions indicate that there is a significant embodied energy advantage to the production of geopolymers from Bayer process liquors. This advantage may reflect a potential commercial advantage allowing large scale utilisation of this low carbon technology. Further investigation is warranted as production opportunities arise. Moreover, there may be a specific argument for adjusting alumina production from a crossindustry or industrial symbiosis perspective. Further research is recommended to identify the system-wide impacts of undertaking such a process alteration, expanding the scope to include both the production of alumina and the production of geopolymer.

There are many barriers present that are slowing down the adoption of geopolymer products including little or no information about the embodied energy of this relatively new product. The figures presented in this paper reveal, for the first time, that a geopolymer based in Bayer liquor has significantly lower embodied energy than Ordinary Portland Cement thus removing one of the barriers to adoption. In addition the embodied energy figures for Bayer derived geopolymer are so low that it should act as a catalyst to industry considering moving to the production of this product.

\section{Acknowledgements}


The Authors wish to thank the International Aluminium Institute (IAI) for provision of hydrate production energy data not previously published. In addition, our thanks go to Kirk Moore of Alcoa for determination of the Bayer evaporation energy consumption. 


\section{References}

[1] Dixit, M.; Fernandez-Solis, J.; Lavy, S.; \& Culp, C. (2010). Identification of parameters of embodied energy measurement: A literature review. Energy and Buildings. 42. pp. 1238-1247.

[2] Prusinski, J.R.; Marceau, M.L.; Van Geem, M.G., (2006). Life cycle inventory of slag cement concrete. In Eighth CANMET / ACI International conference on recent advances in concrete technology, American Concrete Institute: Montreal, Canada, 2006; p 362.

[3] Editorial. (2007).The Asian Opportunity. Nature Materials.6. (8). August. pp. 539.

[4] Allwood, J.; Cullen, J.; \& Milford, R. (2010). Options for Achieving a 50\% Cut in Industrial Carbon Emissions by 2050. Environmental Science \& Technology. 44. (6). pp. 888-894.

[5] O’Brien, K.; Ménaché, J.; O’Moore, L., Impact of fly ash content and fly ash transportation distance on embodied greenhouse gas emissions and water consumption in concrete. The International Journal of Life Cycle Assessment. (2009) 14:621-629.

[6] Huntzinger, D.N.; Eatmon, T.D. (2009). A life-cycle assessment of portland cement manufacturing: Comparing the traditional process with alternative technologies. Journal of Cleaner Production, 17, 668-675.

[7] Van den Heede, P.; \& De Belie, N. (2012). Environmental impact and life cycle assessment (LCA) of traditional and green concretes: Literature review and theoretical calculations. Cement and Concrete Composites. 34. pp. 431-442.

[8] CCAA. (2010). Sustainable Concrete Materials, Briefing Note. Cement Concrete \& Aggregates Australia. 11 Apr 2010. pp. 1-8. www.ccaa.com.au/sustainability/document2.pdf. Retrieved November 2012.

[9] Davidovits, J. (1994). Properties of Geopolymer Cements. Proceedings of the First International Conference on Alkaline Cements and Concretes. Kiev, Ukraine. 1994. pp. 131-149

[10] Wimpenny, D. (2009). Low carbon concrete-options for the next generation of infrastructure. Concrete Solutions 09. Sydney, Australia. 17-19 September.Paper 41-1. pp. 1-10.

[11] Weil, M.; Dombrowski, K.; \& Buchwald, A. (2009). Life cycle analysis of geopolymers. Geopolymers structure, processing, properties and industrial applications. Woodhead publishing Ltd CRC.ISBN 978-1-84569-263-6. pp. 194-210.

[12] Zeobond (2012) (http://www.zeobond.com/life-cycle-analysis.html). Retrieved 2012.

[13] Van Deventer, J.; Provis, J.; \& Duxton, P. (2012). Technical and commercial progress in the adoption of geopolymer cement. Minerals Engineering. 29. pp. 89-104.

[14] Wagners Concrete Pty Ltd. (2012). EFC. Earth Friendly Concrete. http://www.wagnerscft.com.au/files/2613/4731/0397/Wagners-Earth-Friendly-Concrete.pdf . Retrieved 03/01/2013. pp. 1-6. 
[15] Yang, K.; Song, J.; \& Song, K. (2013). Assessment of CO2 reduction for alkali-activated concrete. Journal of Cleaner Production. 39. pp. 265-272.

[16] Habert, G.; de Lacaillerie, J.; Lanta, E.; \& Roussel, N. (2010). Environmental evaluation of cement substitution with geopolymers.Second International Conference on Sustainable Construction Materials and Technologies. June, 2010, Ancona, Italy. pp. 1607-1616.

[17] McLellan, B.; Williams, R..; Lay, J.; van Riessen, A. \& Corder, G. (2011).Costs and carbon emissions of geopolymer pastes in comparison to ordinary Portland cement. Journal of Cleaner Production. 19. (9-10). pp. 1080-1090.

[18] USGS. (2011). Mineral commodity summaries; United States Geological Survey: Washington, January 26, 2011. ISBN 978-1-4113-3083-2.

[19] IEA. (2010). Energy balances of non-OECD countries. In International Energy Agency: Paris, France, 2010. ISBN :9789264084117

[20] BP. (2011). BP statistical review of world energy 2011. London 2011. http://www.bp.com/statisticalreview (rietrived June 6, 2011).

[21] Wahyuni, A.; Nikraz, H.; Jamieson, E.; \& Cooling, D. (2006). Sustainable use of residual bauxite tailings sand (red sand) in concrete.Green Processing, 3rd International Conference on Sustainable Processing of Minerals and Metals. Newcastle, Australia. June 2006. pp. 105-122.

[22] Jamieson, E. (2008). Method for management of contaminants in alkaline process liquors. Provisional Patent.WO/2008/017109.

[23] Phair, J., Van Deventer, J. (2002). Characterization of fly ash based geopolymeric binders activated with sodium aluminate. Industrial and Engineering Chemistry Research. 41. (17). pp. 4242-4251.

[24] Jamieson, E.; van Riessen, A.; Kealley, C.; \& Hart, R. (2012). Development of Bayer Geopolymer Paste and use as Concrete. 9th International Alumina Quality Workshop, March 2012, Perth. pp. 296299.

[25] van Riessen, A.; Jamieson, E.; Kealley, C.; Hart, R., \& Williams, R. Bayer-Geopolymers: an exploration of synergy between the alumina and geopolymer industries. Journal of Cement, Concrete \& Composites 41 (2013) 29-33.

[26] McLellan, B.; Corder, G.; Giurco, D.; \& Ishihara, K. (2012). Renewable energy in the minerals industry: A review of global potential. Journal of Cleaner Production, 32, 32-44.

[27] Langer, W.,(2009). Sustainability of aggregates in construction. In Sustainability of construction materials, Khatib, J., Ed. Woodhead Publishing Limited: Cambridge, 2009; pp 1-30.

[28] Alcorn, A. (2001). Embodied energy and $\mathrm{CO}_{2}$ coefficients for NZ building materials. Centre for Building Performance Research. Victoria University of Wellington. ISBN 0-475-11099-4 www.victoria.ac.nz/cbpr/documents/pdfs/ee-coefficients.pdf Retrieved 03/01/2013. pp. 1-23.

[29] Goggins, J.; Keane, T.; \& Kelly, A. (2010). The assessment of embodied energy in typical reinforced concrete building structures in Ireland. Energy and Buildings. 42 pp. 735-744. 
[30] Reddy, B.; \& Jagadish, K. (2003). Embodied energy of common and alternative building materials and technologies. Energy and Buildings. 35. pp.129-137.

[31] Jiao, Y.; Lloyd. C.; \& Wakes, S. (2012). The relationship between total embodied energy and cost of commercial buildings. Energy and Buildings 52 pp. 20-27.

[32] Hammond, G., \& Jones, C. (2011). Inventory of carbon and energy (ICE). Version 2.0. Sustainable Energy Research Team, Department of Mechanical Engineering, University of Bath UK. http://www.naturalstonespecialist.com/documents/ICEV2.0-Jan2011.xls Retrieved February 2013.

[33] Hammond, G., \& Jones, C. (2008a). Inventory of carbon and energy (ICE). Version 1.6a. Sustainable Energy Research Team, Department of Mechanical Engineering, University of Bath UK. http://web.mit.edu/2.813/www/readings/ICE.pdf Retrieved February 2013.

[34] European Commission.(2001). Integrated pollution prevention and control (IPPC). Reference Document on Best Available Techniques in the Chlor-Alkali Manufacturing industry. http://eippcb.jrc.es/reference/BREF/cak_bref_1201.pdf Retrieved 03/01/2013.

[35] Norgate, T.; \& Haque, N. (2010). Energy and greenhouse gas impacts of mining and mineral processing operations. Journal of Cleaner Production. 18, pp. 266-274.

[36] IAI. (2007). Life cycle assessment of aluminium: Inventory data for the primary aluminium industry; International Aluminium Institute. United Kingdom, September, 2007.

[37] McLellan, B. (2012). Using transportation to assess optimal value chain configuration for minimal environmental impact, 2nd World Sustainability Forum, Online, 1 - 30 November, 2012, Rosen, M.A., Ed. MDPI: Online, 2012. www.sciforum.net/presentation/835/pdf.

[38] Smith, M.; Hargroves, K.; Stasinopoulos, P.; Stephens, R.; Desha, C.; \& Hargroves, S. (2007). Engineering Sustainable Solutions Program: Sustainable Energy Solutions Portfolio, The Natural Edge Project. - LECTURE 5.1: Opportunities for energy efficiency in the aluminium, steel and cement sectors. pp. 1-27. http://www.naturaledgeproject.net/Sustainable_Energy_Solutions_Portfolio.aspx Retrieved Feb 2013.

[39] IEA. (2007). Tracking Industrial Energy Efficiency and $\mathrm{CO}_{2}$ Emissions, International Energy Agency / OECD: June, 2007. ISBN :9789264030404.

[40] Milne, G.; \& Reardon, C. (2010). 5.2 Embodied Energy. Australia’s guide to environmentally sustainable homes. A joint initiative of the Australian Government and industry. www.yourhome.gov.au/technical/fs52.html Retrieved 09/08/2012. pp.136-139.

[41] Hammond, G., \& Jones, C. (2008b). Embodied energy and carbon in construction materials. Proceedings of the Institution of Civil Engineers - Energy. 161. (2). pp. 87-98. ISSN 1751-4223

[42] CGA. (2000). Energy efficiency best practice in the Australian aluminium industry: Summary report. Industry, Science and Resources; Energy Efficiency Best Practice Program. July. 2000. A Commonwealth Government Initiative. ISBN 064272041 X. pp. 1-21.

[43] IAI. (2012). Personal communications with International Aluminium Institute. 2012. 


\section{Figures}

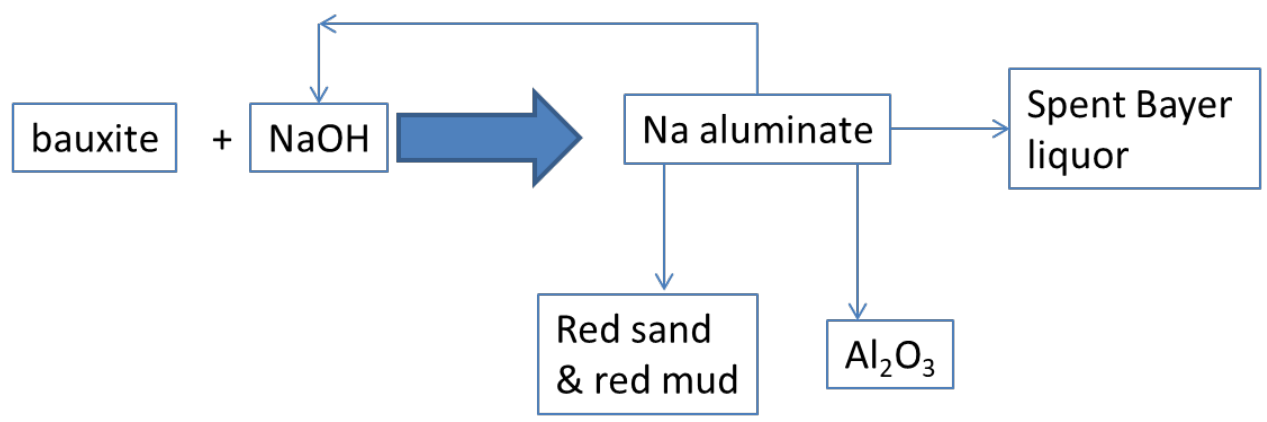

Figure 1: A simplified Bayer flow-sheet showing the geopolymer feedstock and other by-products in the production of alumina. Bayer geopolymer feedstock would typically be less than $1 \%$ of the recirculated liquor flow. 